\title{
Diffuse panbronchiolitis in rheumatoid arthritis
}

\author{
S. Homma*, M. Kawabata*, K. Kishi*, E. Tsuboi*, K. Narui*, T. Nakatani*, \\ T. Uekusa**, S. Saiki**, K. Nakata*
}

Diffuse panbronchiolitis in rheumatoid arthritis. S. Homma, M. Kawabata, K. Kishi, E. Tsuboi, K. Narui, T. Nakatani, T. Uekusa, S. Saiki, K. Nakata. (OERS Journals Ltd 1998. ABSTRACT: The association of progressive obliterative bronchiolitis (OB) with rheumatoid arthritis (RA) is uncommon but has been reported previously. Diffuse panbronchiolitis (DPB) is a unique inflammation principally affecting the respiratory bronchioli and has been reported mainly in Japanese adults. Recently, DPB has also been noted in patients with RA in Japan. Therefore, there might be considerable overlap in clinical features between DPB and OB associated with RA in Japan. The aim of this study was to evaluate the clinicopathological characteristics of bronchiolitis in patients with RA.

Three RA patients clinically diagnosed as having DPB were evaluated. All patients underwent chest radiographs, pulmonary function tests (PFT) and post mortem examination.

Clinical features in all patients were a history of productive cough, exertional dyspnoea, wheezing and/or coarse crackles. Chest radiographs showed small nodular shadows up to $2 \mathbf{~ m m}$ in diameter with bronchiolectasis throughout both lungs in all patients. The PFT revealed marked obstructive impairment in all patients. All patients died of progressive respiratory failure. Pathologically, two out of the three cases were confirmed as DPB, while the remaining one case was confirmed as $\mathrm{OB}$, because the primary obstructive lesions were in the respiratory bronchioli in the former and in the membranous bronchioli and the proximal small bronchi in the latter. Thus, the clinical features of DPB and OB were strikingly similar, but the histopathological features revealed distinct differences.

This study demonstrated that there was considerable overlap in clinical features between diffuse panbronchiolitis and obliterative bronchiolitis associated with rheumatoid arthritis, suggesting that diffuse panbronchiolitis might be a new manifestation of rheumatoid arthritis. The differentiation of these two disease entities is significant in making decisions on their therapeutic modality and is possible by analysing the precise histopathological findings of the lung. Eur Respir J 1998; 12: 444-452.

The pulmonary manifestations of rheumatoid arthritis (RA), including pleuritis, rheumatic nodules, pneumonitis and vasculitis [1], are well known. However, progressive airway obliteration related to obliterative bronchiolitis (OB) with a concentric narrowing of the lumina of the membranous bronchioles producing fatal obstructive lung disease is uncommon and has been noted in a small number of patients with RA, mainly female patients in Europe [2, 3] and America [4]. In contrast, diffuse panbronchiolitis (DPB), a disease principally affecting the respiratory bronchioli and causing a severe obstructive respiratory disorder, has been reported mainly in Japan [5-7]. Recently, the first autopsy case of DPB accompanying RA has been recognized in Japan [8], suggesting that DPB may be another manifestation of RA. There may be considerable overlap between DPB and OB associated with RA in Japan, but only little is known about the nature and evolution of these airway diseases [9]. In fact, one of the three cases after autopsy in the present study turned out to be OB after histopathological examination. The aim of this study was to clarify the clinicopathological characteristics of bronchiolitis in patients with RA.
*Division of Respiratory Diseases, Toranomon Hospital, Tokyo, Japan. **Dept of Pathology, St Luke's International Hospital, Tokyo, Japan

Correspondence: S. Homma

Division of Respiratory Diseases

Toranomon Hospital

Toranomon 2-2-2, Minato-ku

Tokyo 105

Japan

Fax: 81335827068

Keywords: Bronchiolitis diffuse panbronchiolitis obliterative bronchiolitis rheumatoid arthritis

Received: January 131997 Accepted after revision March 201998

Supported by a grant to $\mathrm{S}$. Homma from the Toranomon Hospital Research Foundation/95 in Japan.
Subjects and methods

Between May 1977 and November 1996, six patients (four males and two females) with RA were clinically diagnosed as having DPB. Three out of these six patients underwent post mortem examination. These three cases are presented and the association of DPB and OB with RA is discussed. DPB was diagnosed using the clinical diagnostic criteria established with the aid of the Ministry of Health and Welfare of Japan [10]: 1) cough, sputum and shortness of breath on exertion; 2) moist and dry rales on the chest; 3 ) chest radiographic findings of diffuse scattered granular shadows in bilateral lung fields and hyperinflation [11]; and 4) pulmonary function tests of diminution in forced expiratory volume in one second (FEV1)\% (below $70 \%$ ), diminution of vital capacity (below $80 \%$ of predicted value), increase in residual air above $150 \%$ of predicted value and hypoxaemia (below $10.6 \mathrm{kPa}$ (80 $\mathrm{mmHg})$ ). To establish the diagnosis, at least three of these criteria must be met. Additional features such as chronic parasinusitis, elevation of cold haemagglutinin titre, CD4/ CD8 ratio, immunoglobulin (Ig)A and proof of human 
leukocyte antigen (HLA)-B54 antigen are frequently present. Such clinical findings can be used in making the diagnosis of DPB. Histological studies, when possible, can confirm the diagnosis. Chronic bronchitis, bronchial asthma and chronic emphysema should be carefully ruled out.

RA was diagnosed based on the revised criteria of the American Rheumatism Association in 1987 [12]. The new criteria are as follows: 1) morning stiffness in and around joints lasting for at least $1 \mathrm{~h}$ before maximal improvement; 2) soft tissue swelling (arthritis) of three or more joint areas observed by a physician; 3) swelling (arthritis) of the proximal interphalangeal, metacarpophalangeal or wrist joints; 4) symmetric swelling (arthritis); 5) rheumatoid nodules; 6) the presence of rheumatoid factor; and 7) radiographic erosions and/or periarticular osteopenia in hand and/or wrist joints. RA is defined by the presence of four or more of these criteria.

\section{Radiography}

Chest radiographs and/or chest computed tomographic (CT) images before treatment were evaluated.

\section{Pulmonary function tests}

Lung volume, FEV1, maximal midexpiratory flow and blood gas studies were carried out according to standard methods with a Chestac-55V (Chest Co., Tokyo, Japan) and ABL510 (Radiometer Co., Copenhagen, Denmark).

\section{Morphological analysis}

All three patients underwent post mortem examination and one patient also underwent transbronchial lung biopsy performed as an initial diagnostic procedure. At autopsy, the lungs were inflated with a fixative (10\% formaldehyde) at $30 \mathrm{cmH}_{2} \mathrm{O}$ via a tracheal cannula. After fixation for $48 \mathrm{~h}, 5 \mathrm{~mm}$ serial sections along each bronchus were obtained from all segments of both lungs for the reconstruction studies of the primary obstructive lesions of the bronchioli. Tissue samples were embedded in paraffin, from which $3 \mu \mathrm{m}$ thick sections were cut and stained with haematoxylin-eosin (H\&E) and Elastica van Gieson. Sections were mounted in aqueous mounting medium and observed by light microscopy to determine the characteristics of bronchiolitis.

Clinical findings, radiographic images, results of pulmonary function tests and pathological findings were analysed and compared according to the diagnosis of DPB associated with RA.

\section{Results}

\section{Clinical findings}

The clinical features of the two patients with DPB and one patient with $\mathrm{OB}$ (one male and two females; mean age $62.3 \pm 2.3 \mathrm{yrs}$ ) in association with RA are shown in tables 1 and 2. The duration between the onset of RA symptoms and respiratory symptoms was $0-13$ yrs in two cases and respiratory symptoms preceded RA symptoms in one case (case 1). All patients died of progressive respiratory failure within 4-30 yrs after the onset of respiratory symptoms. There was no close relationship with smoking or inhalation of toxic dust. Chronic parasinusitis was diagnosed in two out of three patients. Initial respiratory symptoms were cough and tenacious sputum in all patients

Table 3. - Chest radiographic findings

\begin{tabular}{|c|c|c|c|c|}
\hline $\begin{array}{l}\text { Case } \\
\text { No. }\end{array}$ & $\begin{array}{c}\text { Small } \\
\text { nodular } \\
\text { shadows }\end{array}$ & Tramlines & $\begin{array}{c}\text { Bronchio- } \\
\text { lectasis }\end{array}$ & $\begin{array}{l}\text { Hyper- } \\
\text { inflation }\end{array}$ \\
\hline $\begin{array}{l}1 \\
\text { (DPB with RA) }\end{array}$ & + & + & + & + \\
\hline (DPB with RA) & + & + & + & - \\
\hline $\begin{array}{l}3 \\
\text { (OB with RA) }\end{array}$ & + & + & + & + \\
\hline
\end{tabular}

DPB: diffuse panbronchiolitis; RA: rheumatoid arthritis; OB: obliterative bronchiolitis.

Table 1. - Clinical features (1)

\begin{tabular}{|c|c|c|c|c|c|c|c|c|}
\hline $\begin{array}{l}\text { Case } \\
\text { No. }\end{array}$ & $\begin{array}{l}\text { Age } \\
\text { yrs }\end{array}$ & Sex & $\begin{array}{c}\text { Clinical } \\
\text { diagnosis }\end{array}$ & $\begin{array}{l}\text { Pathological } \\
\text { diagnosis }\end{array}$ & $\begin{array}{l}\text { Respiratory } \\
\text { symptoms }\end{array}$ & $\begin{array}{l}\text { RA to respiratory } \\
\text { symptoms } \\
\text { yrs }\end{array}$ & $\begin{array}{c}\text { Respiratory symptoms } \\
\text { to death } \\
\text { yrs }\end{array}$ & Cause of death \\
\hline 1 & 61 & $\mathrm{~F}$ & $\begin{array}{l}\text { DPB } \\
\text { RA }\end{array}$ & $\begin{array}{l}\text { DPB } \\
\text { RA }\end{array}$ & $\begin{array}{l}\text { Cough } \\
\text { Sputum }\end{array}$ & -12 & 30 & $\begin{array}{c}\text { Respiratory failure } \\
2 \text { May } 1977\end{array}$ \\
\hline 2 & 61 & M & $\begin{array}{l}\text { DPB } \\
\text { RA }\end{array}$ & $\begin{array}{l}\text { DPB } \\
\text { RA }\end{array}$ & $\begin{array}{l}\text { Dyspnoea } \\
\text { Sputum }\end{array}$ & 0 & 4 & $\begin{array}{c}\text { Respiratory failure } \\
\text { 9 February } 1985\end{array}$ \\
\hline 3 & 65 & $\mathrm{~F}$ & $\begin{array}{l}\text { DPB } \\
\text { RA }\end{array}$ & $\begin{array}{l}\text { OB } \\
\text { RA }\end{array}$ & $\begin{array}{l}\text { Cough } \\
\text { Sputum }\end{array}$ & 13 & 6 & $\begin{array}{c}\text { Respiratory and renal failure } \\
10 \text { August } 1983\end{array}$ \\
\hline
\end{tabular}

F: female; M: male; DPB: diffuse panbronchiolitis; RA: rheumatoid arthritis; OB: obliterative bronchiolitis.

Table 2. - Clinical features (2)

\begin{tabular}{|c|c|c|c|c|c|c|c|c|}
\hline $\begin{array}{l}\text { Case } \\
\text { No. }\end{array}$ & SI & Dust & $\begin{array}{c}\text { Chronic } \\
\text { parasinusitis }\end{array}$ & CHA & $\begin{array}{l}\text { Sputum } \\
\mathrm{g} \cdot \mathrm{day}^{-1}\end{array}$ & $\begin{array}{l}\text { Sputum } \\
\text { culture }\end{array}$ & Treatment & $\begin{array}{c}\text { HLA } \\
\text { B54 DR4 }\end{array}$ \\
\hline $\begin{array}{l}1 \\
\text { (DPB with RA) }\end{array}$ & - & - & $(+)$ & X512 & 70 & $\begin{array}{l}\text { H. influenzae } \\
P \text {. aeruginosa }\end{array}$ & $\begin{array}{c}\text { Steroid } \\
\text { Gold }\end{array}$ & $\mathrm{NE}$ \\
\hline $\begin{array}{l}2 \\
\text { (DPB with RA) }\end{array}$ & - & - & $(-)$ & X512 & 150 & $\begin{array}{l}\text { H. influenzae } \\
\text { P. aeruginosa }\end{array}$ & $\begin{array}{c}\text { Steroid } \\
\text { Penicillamine }\end{array}$ & $\mathrm{NE}$ \\
\hline 3 & - & - & $(+)$ & X2048 & 100 & $\begin{array}{l}\text { H. influenzae } \\
\text { P. aeruginosa }\end{array}$ & $\begin{array}{l}\text { Steroid } \\
\text { Gold }\end{array}$ & $\mathrm{NE}$ \\
\hline
\end{tabular}

SI: smoking index; CHA: cold haemagglutinin; HLA: human leukocyte antigen; DPB: diffuse panbronchiolitis; RA: rheumatoid arthritis; $\mathrm{OB}$ : obliterative bronchiolitis; H. influenzae: Haemophilus influenzae; P. aeruginosa: Pseudomonas aeruginosa; NE: not examined. 
Table 4. - Pulmonary function tests

\begin{tabular}{lccccc}
\hline $\begin{array}{l}\text { Case } \\
\text { No. }\end{array}$ & $\begin{array}{c}\mathrm{VC} \\
\mathrm{L}(\%)\end{array}$ & $\begin{array}{c}\mathrm{FEV} 1(\mathrm{FEV}) \%) \\
\mathrm{L}(\%)\end{array}$ & $\begin{array}{c}\mathrm{RV} / \mathrm{TLC} \\
\%\end{array}$ & $\begin{array}{c}\mathrm{MMEF} \\
\mathrm{L} \cdot \mathrm{s}^{-1}\end{array}$ & $\begin{array}{c}P_{\mathrm{a}, \mathrm{O}_{2} / P \mathrm{a}, \mathrm{CO}_{2}} \\
\mathrm{mmHg}\end{array}$ \\
\hline 1 & $1.74(72)$ & $0.48(28)$ & 60 & $\mathrm{NE}$ & $54 / 48$ \\
(DPB with RA) & $1.28(41)$ & $0.59(46)$ & 61 & 0.2 & $68 / 42$ \\
2 & $2.20(94)$ & $1.45(66)$ & 48 & 0.97 & $79 / 36$ \\
$\begin{array}{l}\text { (DPB with RA) } \\
\text { (OB with RA) }\end{array}$ & $\begin{array}{l}1.74 \pm 0.46 \mathrm{~L} \\
\text { Mean } \pm \text { SD }\end{array}$ & $\begin{array}{c}0.84 \pm 0.53 \mathrm{~L} \\
(46.6 \pm 19.0 \%)\end{array}$ & $56.3 \pm 7.2$ & $0.59 \pm 0.54$ & $67.0 \pm 12.5 / 42.0 \pm 6.0$ \\
\hline
\end{tabular}

VC: vital capacity; FEV1: forced expiratory volume in one second; RV: residual volume; TLC: total lung capacity; MMEF: maximum midexpiratory flow; $\mathrm{Pa}, \mathrm{O}_{2}$ : arterial oxygen tension; $\mathrm{Pa}_{2} \mathrm{CO}_{2}$ : arterial carbon dioxide tension; DPB: diffuse panbronchiolitis; RA: rheumatoid arthritis; OB: obliterative bronchiolitis; NE: not examined. $1 \mathrm{mmHg}=0.133 \mathrm{kPa}$.

Table 5. - Pathological findings

\begin{tabular}{|c|c|c|c|c|c|}
\hline \multirow{2}{*}{$\begin{array}{l}\text { Case } \\
\text { No. }\end{array}$} & \multicolumn{2}{|c|}{ Primary obstructive lesions } & \multirow[t]{2}{*}{ FB } & \multirow{2}{*}{$\begin{array}{c}\text { Clinical diagnosis/ } \\
\text { pathological diagnosis }\end{array}$} & \multirow{2}{*}{$\begin{array}{l}\text { Sampling method for } \\
\text { lung specimens }\end{array}$} \\
\hline & $\begin{array}{l}\text { Respiratory } \\
\text { bronchioli }\end{array}$ & $\begin{array}{c}\text { Membranous } \\
\text { bronchioli }\end{array}$ & & & \\
\hline $\begin{array}{l}\text { (DPB with RA) } \\
\text { (D) }\end{array}$ & + & - & - & DPB/DPB & Autopsy \\
\hline (DPB with RA) & + & - & - & $\mathrm{DPB} / \mathrm{DPB}$ & TBLB and autopsy \\
\hline (OB with RA) & - & + & - & $\mathrm{DPB} / \mathrm{OB}$ & Autopsy \\
\hline
\end{tabular}

FB: follicular bronchiolitis; DPB: diffuse panbronchiolitis; RA: rheumatoid arthritis; TBLB: transbronchial lung biopsy; OB: obliterative bronchiolitis.

patients. The mean amount of sputum production was as large as $107 \mathrm{~g} \cdot$ day $^{-1}$. Physical signs of wheezing and/or coarse crackles were auscultated on the chest in all patients. Haemophilus influenzae or Pseudomonas aeruginosa superinfection appeared in the sputum of all patients. Elevation of the cold haemagglutinin titre by more than 512 -fold was observed in all three patients. Corticosteroid or gold therapy for RA was applied in all patients and penicillamine therapy was applied in one patient.

\section{Radiography}

Chest radiographic and/or CT images showed small nodular shadows up to $5 \mathrm{~mm}$ in diameter with tram lines and bronchiolectasis throughout both lungs in all patients. The incidence of hyperinflation were found in two out of three patients (table 3 ).

\section{Pulmonary function tests}

Pulmonary function tests at the first visit revealed marked obstructive impairment, slight restrictive impairment and hypoxaemia in all patients (table 4).

\section{Pathological findings}

All three patients died of progressive respiratory failure within 4-30 yrs after the onset of respiratory symptoms and underwent post mortem examination. Post mortem examination of the lungs in two patients (cases 1 and 2) showed thickening of the walls of the respiratory bronchioli with infiltration of lymphocytes, plasma cells and histiocytes associated with secondary ectasis of the proximal terminal bronchioli. The lungs in the other patient (Case 3 ) showed obliteration and destruction of the membranous

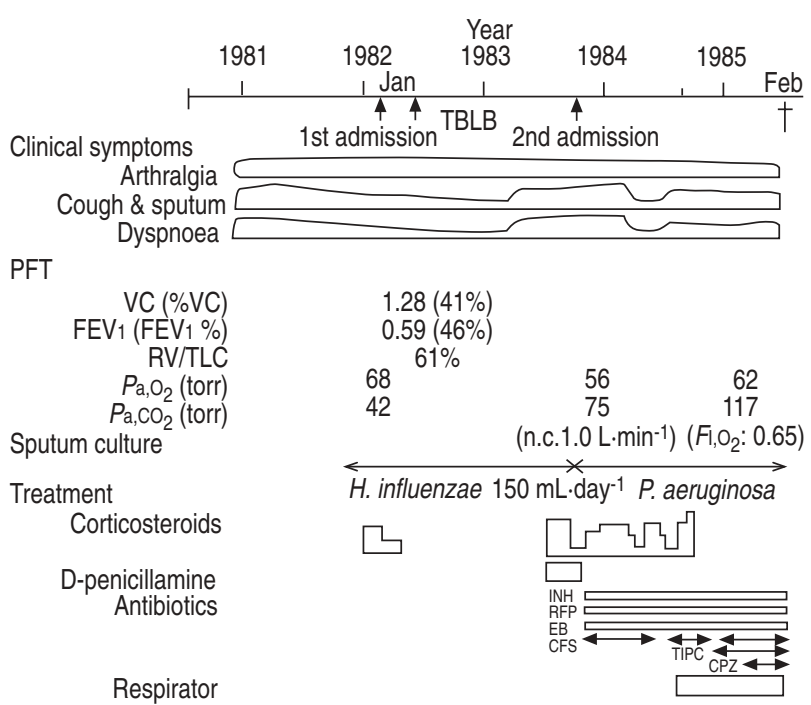

Fig. 1. - Clinical course in case 2. TBLB: transbronchial lung biopsy; PFT: pulmonary function test; VC: vital capacity; FEV 1 : forced expiratory volume in one second; RV: residual volume; TLC: total lung capacity; $\mathrm{Pa}, \mathrm{O}_{2}$ : arterial oxygen tension; $\mathrm{Pa}_{\mathrm{a}} \mathrm{CO}_{2}$ : arterial carbon dioxide tension; $F_{\mathrm{I}, \mathrm{O}_{2}}$ : inspiratory oxygen fraction; n.c.: nasal cannula; $H$. influenzae: Haemophilus influenzae; P. aeruginosa: Pseudomonas aeruginosa; INH: isoniazid; RFP: rifampicin; EB: ethambutol hydrochloride; CFS: cefsulosin sodium; TIPC: ticarcillin sodium; CPZ: cefoperazone sodium. 1 torr $=0.1332 \mathrm{kPa}$.

bronchioli by granulation tissues, but the distal respiratory bronchioli were spared. Therefore, two of the three patients with a clinical diagnosis of DPB (cases 1 and 2) were confirmed as having DPB while the third was found to have $\mathrm{OB}$ (case 3 ). The primary obstructive lesions were in the respiratory bronchioli in those confirmed to have DPB and in the membranous bronchioli and the proximal small bronchi in the patient with OB (table 5). 
a)

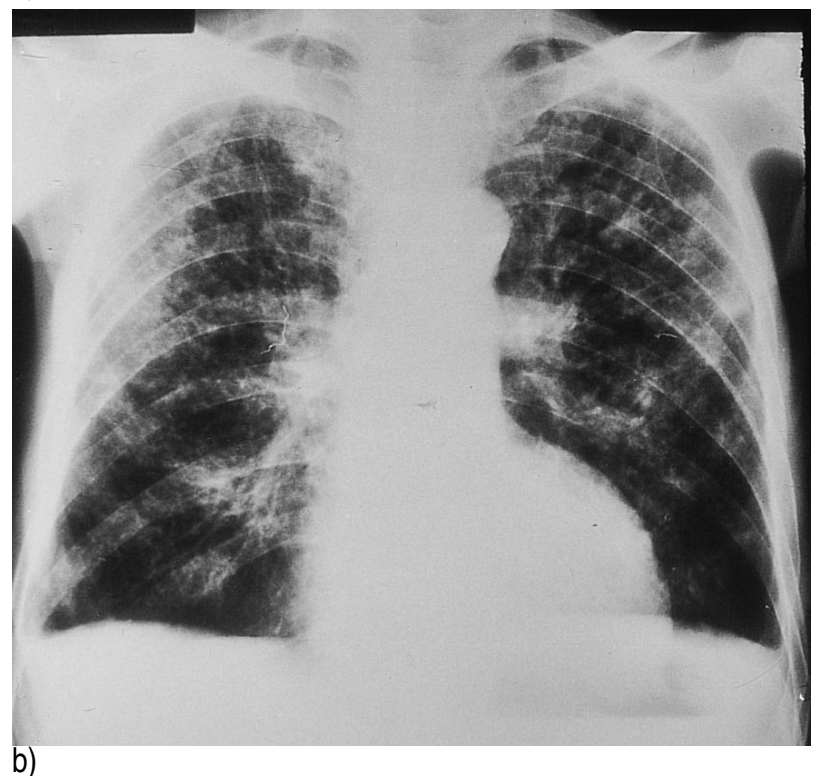

b)

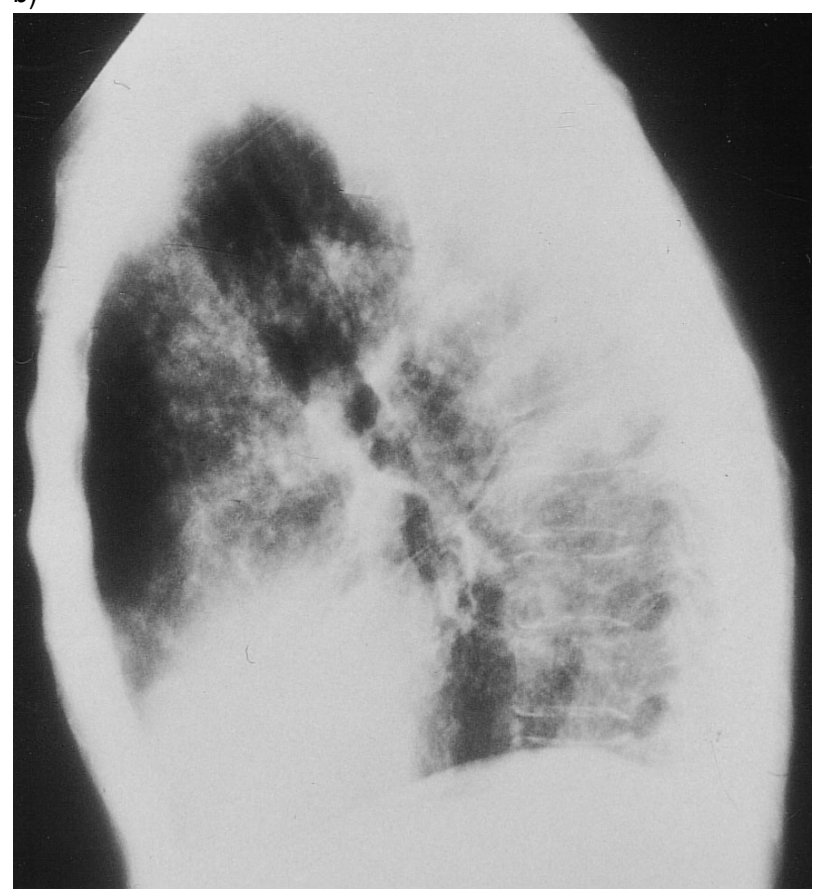

Fig. 2. - Chest radiograph on admission, showing hyperlucency associated with tramlines and scattered fine nodular densities in both lung fields. a) $\mathrm{P} \rightarrow \mathrm{A}$ view; b) $\mathrm{R} \rightarrow \mathrm{L}$ view.

\section{Case reports}

Characteristic clinical and pathological features in the two patients who were finally diagnosed as having DPB and $\mathrm{OB}$ associated with RA are demonstrated.

Case 2. A $61 \mathrm{yr}$ old woodworker visited our hospital because of dyspnoea on exertion, cough and sputum. There was no history of chronic parasinusitis, toxic fume inhalation or cigarette smoking. At the age of $57 \mathrm{yrs}$, the patient experienced generalized joint pains and was then diagnosed as having RA. The patient was admitted for the first time in 1982 because of progressive dyspnoea

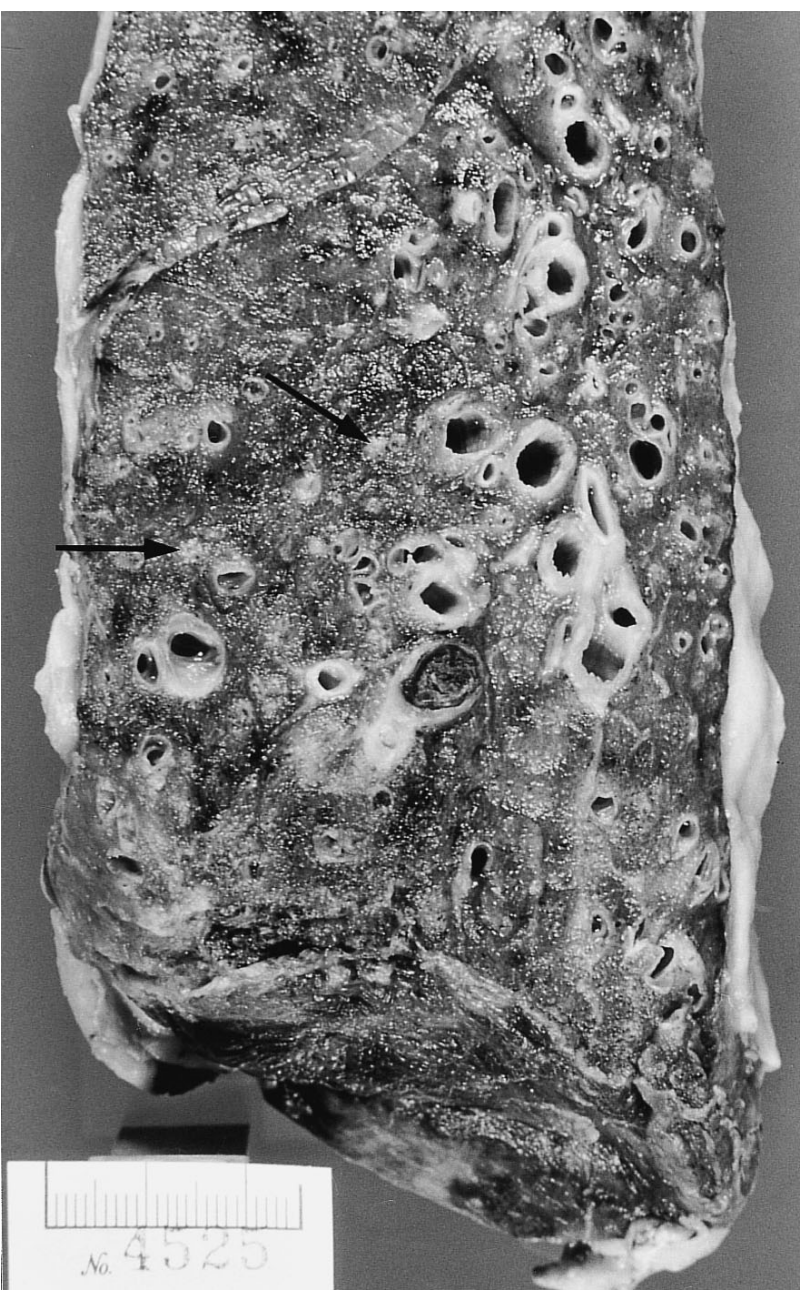

Fig. 3. - On autopsy the macroscopic appearance of the cut surface of the lung, showing multiple fine, yellowish nodules in the centrilobular lesions of up to $2-3 \mathrm{~mm}$ in diameter (arrows), representing respiratory bronchiolitis and peribronchiolitis associated with proximal bronchiolectasis. (Scale: 1 division=1 $\mathrm{mm}$ ).

on exertion and was diagnosed as having DPB associated with

RA, which was confirmed by transbronchial lung biopsy. In 1983, the patient was admitted for the second time because of progressive dyspnoea. Physical examination showed coarse crackles and wheezing in the bilateral lower lung fields. The clinical course of the patient with a duration of 4 yrs from the patient's first visit to death, is shown in figure 1. Pulmonary function tests revealed a marked mixed ventilatory impairment and early hypoxaemia, later accompanied by hypercapnia. Sputum culture revealed $H$. influenzae infection in the initial stage, later followed by $P$. aeruginosa superinfection. In spite of intensive treatment, including the administration of antibiotics and corticosteroids, oxygen inhalation and the use of a respirator, the patient died of refractory respiratory failure in 1985. Chest radiography on admission showed hyperlucency associated with tramlines and scattered fine nodular densities in both lung fields (fig. 2). On autopsy, the macroscopic appearance of the cut surface of the lung showed multiple fine, yellowish nodules in the centrilobular lesions up to $2-3 \mathrm{~mm}$ in diameter, indicating respiratory bronchiolitis and peribronchiolitis associated with proximal bronchiolectasis (fig. 3). 


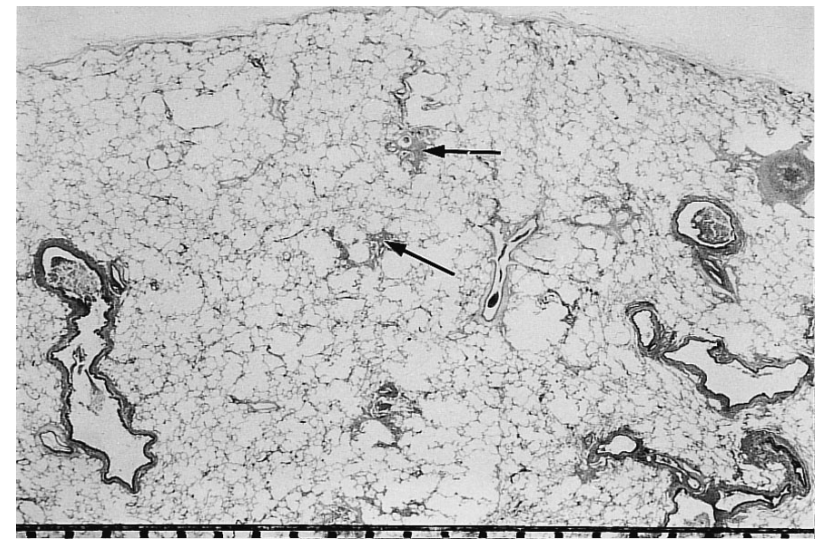

Fig. 4. - Low magnification microscopy, showing that the lesion is limited exclusively to the area of the respiratory bronchiole (arrows) associated with proximal bronchiolectasis. The alveolar spaces are slightly overinflated, but without any destruction (Elastica van Gieson stain). (Scale: 1 division=1 $\mathrm{mm}$ ).

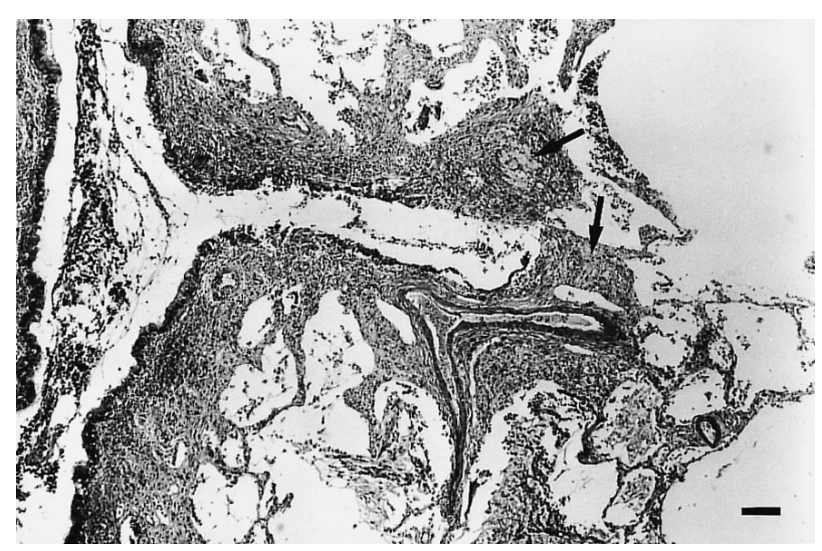

Fig. 5. - Primary lesions, showing that the wall of a respiratory bronchiole is thickened by infiltration of lymphocytes and plasma cells, accompanied by an accumulation of foamy cells (arrows) (Haematoxylin-Eosin stain). (Internal scale bar $=120 \mu \mathrm{m}$ ).

Microscopy at a low magnification showed that the lesion was exclusively limited to the area of the respiratory bronchioles accompanying proximal bronchiolectasis. The alveolar spaces were slightly overinflated, but without destruction (fig. 4). The appearance of the primary lesions under higher magnification showed thickening of the respiratory bronchioles by the infiltration of lymphocytes and plasma cells, accompanied by an accumulation of lipidladen macrophages (foamy cells) (fig. 5). These lesions correspond to the fine, yellowish nodules observed macroscopically on the cut surface of the lung. A schematic reconstruction of the serial sections focusing on the primary lesions showed respiratory bronchiolitis and peribronchiolitis associated with ectasis of the proximal membranous

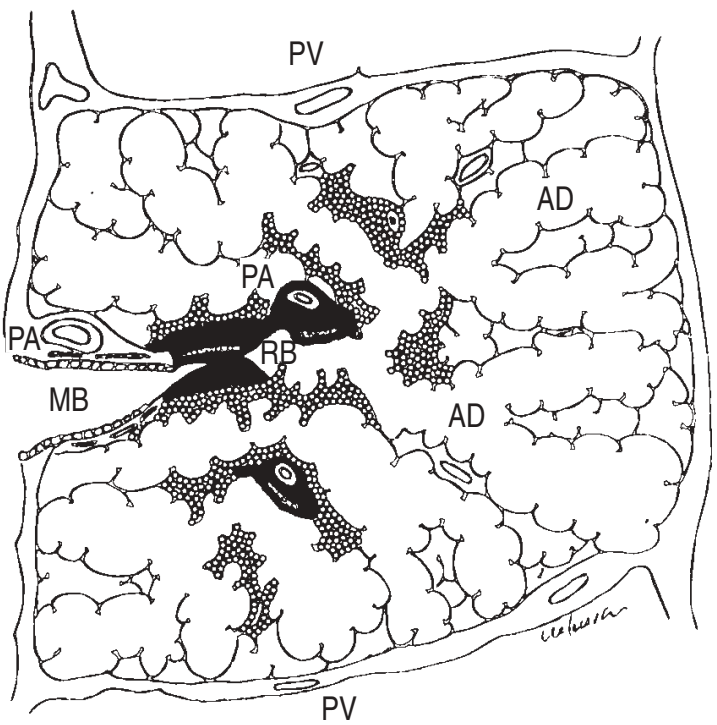

Fig. 6. - Schematic reconstruction of serial sections focusing on the primary lesions, showing respiratory bronchiolitis and peribronchiolitis associated with ectasis of the proximal membranous bronchioli. AD: alveolar duct; MB: membranous bronchiole; PA: pulmonary artery; PV: pulmonary vein; RB: respiratory bronchiole; $\bullet$ : lymphocytes and plasma cells; o: foamy cells.

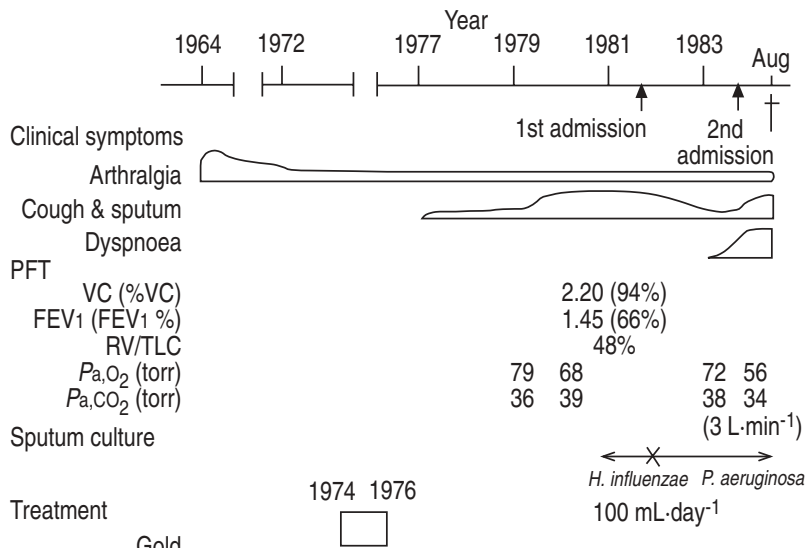

Gold
Operation
Corticosteroids
Antibiotics
Respirator

$\square$ Replacement of knee joints

Fig. 7. - Clinical course in case 3. PFT: pulmonary function test; VC vital capacity; $\mathrm{FEV}_{1}$ :forced expiratory volume in one second; $\mathrm{RV}$ : residual volume; TLC: total lung capacity; $\mathrm{Pa}_{\mathrm{a}} \mathrm{O}_{2}$ : arterial oxygen tension; $\mathrm{Pa}_{\mathrm{a}} \mathrm{CO}_{2}$ : arterial carbon dioxide tension; $H$. influenzae: Haemophilus influenzae; P. aeruginosa: Pseudomonas aeruginosa; CPZ: cefoperazone sodium; PIPC: piperacillin sodium; CFS: cefsulosin sodium; CMX: cefuroxime sodium; DOXY: doxycycline hydrochloride. 1 torr: $0.133 \mathrm{kPa}$. 


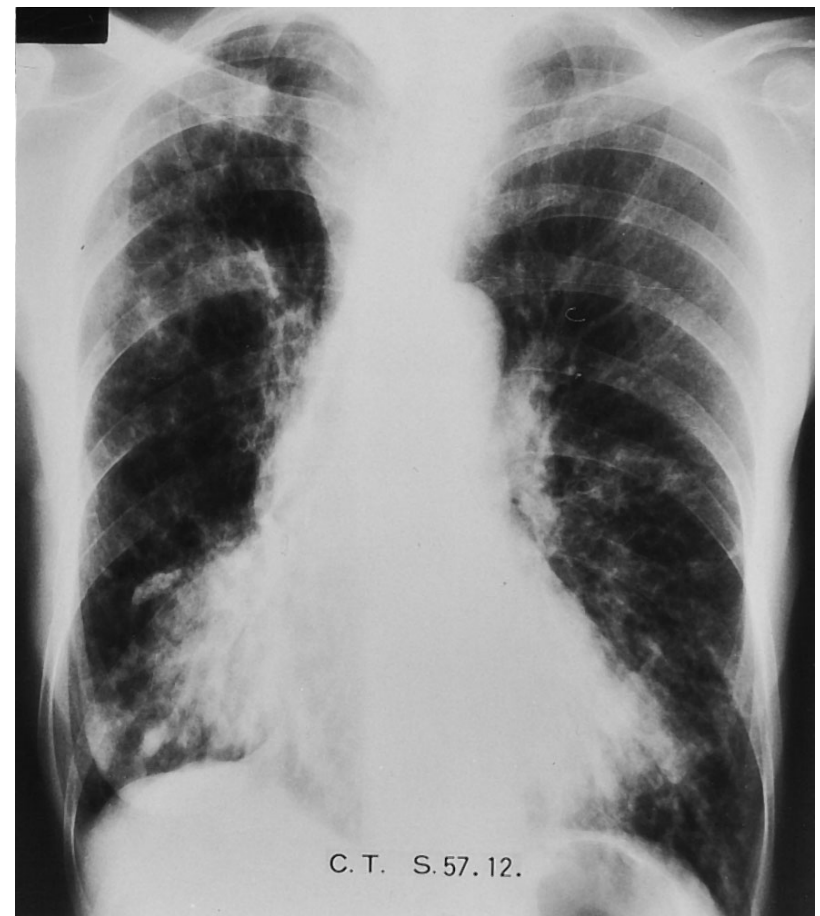

Fig. 8. - Chest radiograph on admission, showing hyperinflation associated with tramlines and scattered, fine, nodular shadows in both lung fields. bronchioli (fig. 6). According to these pathological findings, this case was diagnosed as typical DPB.

Case 3. A 65 yr old nonsmoking female homemaker attended because of dyspnoea on exertion, cough and sputum. The patient had a history of chronic parasinusitis. Since the age of $46 \mathrm{yrs}$, the patient had had joint pains in the hands and was diagnosed as having RA in 1972. The patient underwent knee replacements in 1979, and was admitted to the hospital for the first time in 1982 because of a productive cough and was diagnosed as having DPB associated with RA. In 1983, the patient was admitted for the second time because of progressive dyspnoea. Physical examination showed coarse crackles in the bilateral lower lung fields and swelling of the hands with ulnar deviation. The clinical course of the patient, with a duration of $19 \mathrm{yrs}$ from initial joint symptoms to death, is shown in figure 7 . Pulmonary function tests revealed obstructive impairment with early hypoxaemia. Sputum culture revealed $H$. influenzae infection followed by $P$. aeruginosa super-infection. In spite of intensive treatment, the patient died of refractory respiratory failure in 1983, 6 yrs after the onset of respiratory symptoms. Chest radiography on admission showed hyperinflation associated with tramlines and scattered fine, nodular shadows in the both lung fields (fig. 8).

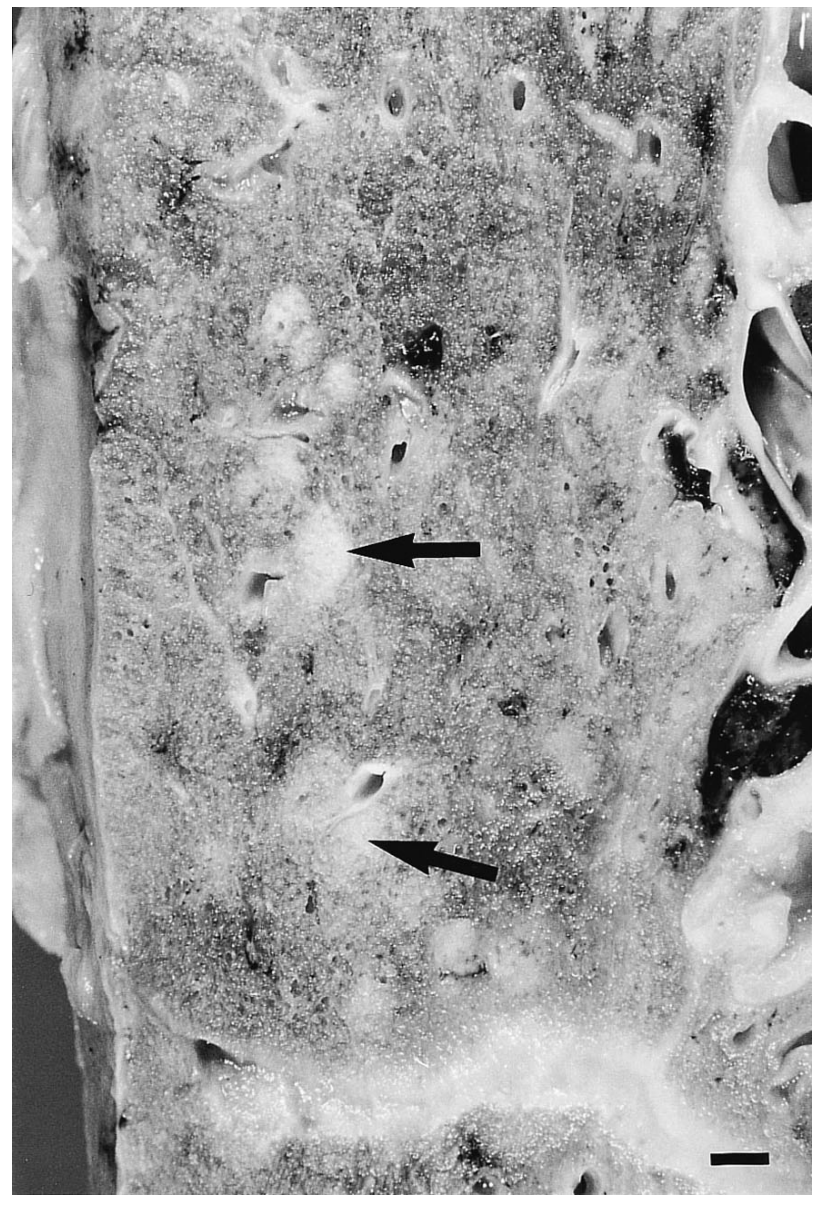

Fig. 9. - Macroscopic appearance of the right upper lobe under higher magnification, showing multiple yellowish-white nodules in the centrilobular lesion (arrows) corresponding to the obliteration of the small bronchioli along the pulmonary arteries. (Internal scale bar=1 mm).

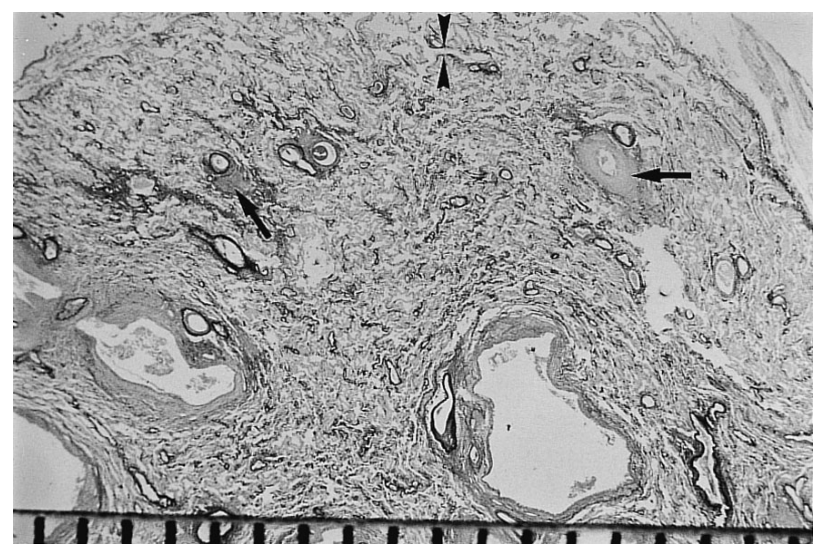

Fig. 10. - Microscopic appearance with low magnification, showing that the lesions are limited exclusively to the area of the membranous bronchioli (arrows) associated with proximal bronchiolectasis, that the distal respiratory bronchioli (arrowheads) are normal (Elastica van Gieson stain). (Scale: 1 division=1 mm). 


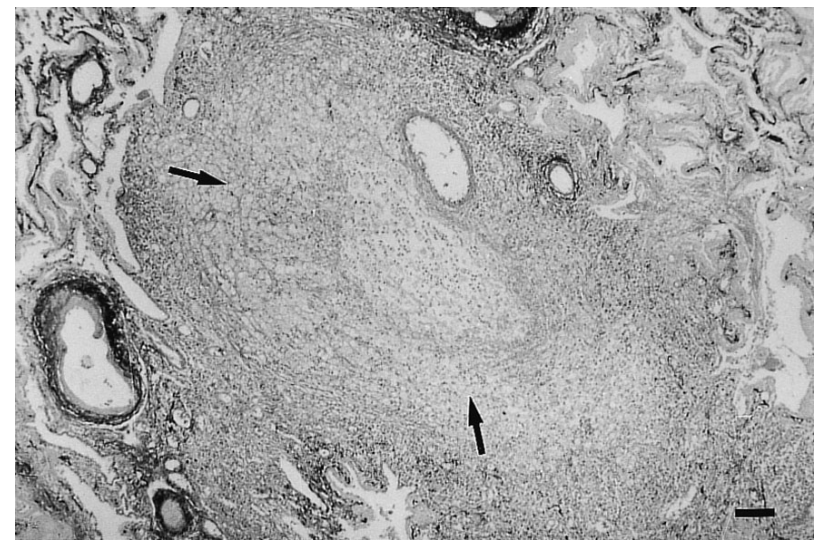

Fig. 11. - Microscopic appearance of the primary lesion, showing that the lumen of a membranous bronchiole is obliterated and its wall destroyed by granulation tissues with an accumulation of foamy cells (arrows) (Elastica van Gieson stain). (Internal scale bar=120 $\mu \mathrm{m}$ ).

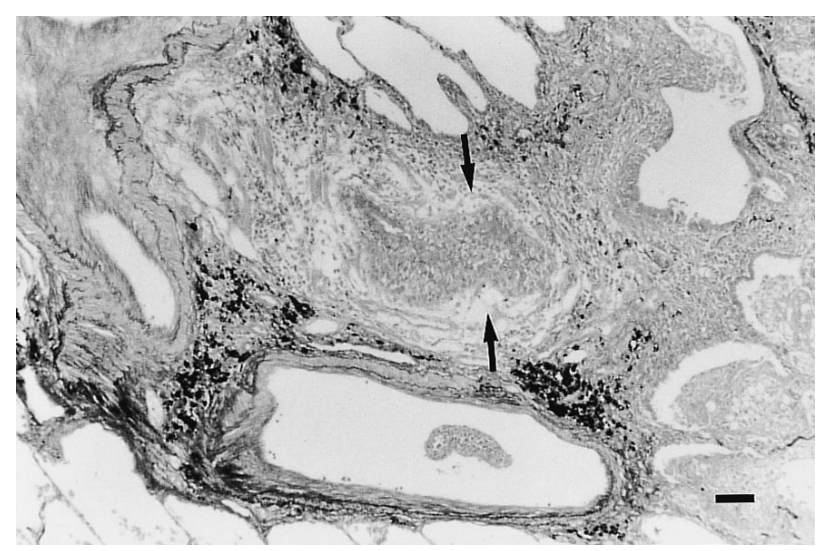

Fig. 12. - Microscopic appearance of another primary lesion, showing that the lumen of a terminal bronchiole is obliterated by granulation tissues (arrows) (Elastica van Gieson stain). (Internal scale bar $=90 \mu \mathrm{m}$ ).

The highly magnified macroscopic appearance of the right upper lobe showed multiple white-yellowish nodules in the centrilobular lesion corresponding to the obliteration of the small bronchioli along the pulmonary arteries (fig. 9). The microscopic appearance under low magnification showed that the lesions were exclusively limited to the area of the membranous bronchioli associated with proximal bronchiolectasis, but the distal respiratory bronchioli were spared (fig. 10). The higher magnification revealed that the primary lesion obliterated the lumen of the membranous bronchiole and its wall was destroyed by granulation tissues with an accumulation of foamy cells (figs. 11 and 12). This corresponds to the fine, yellowish nodules observed macroscopically on the cut surface of the lung. The schematic reconstruction of the serial sections focusing on the primary lesions showed that the lumina of membranous bronchioli were obliterated by granulation tissues, but the distal respiratory bronchioli were spared and alveolar spaces were slightly overinflated (fig. 13). According to these pathological findings, this case was diagnosed as $\mathrm{OB}$, instead of the DPB clinically diagnosed prior to death.

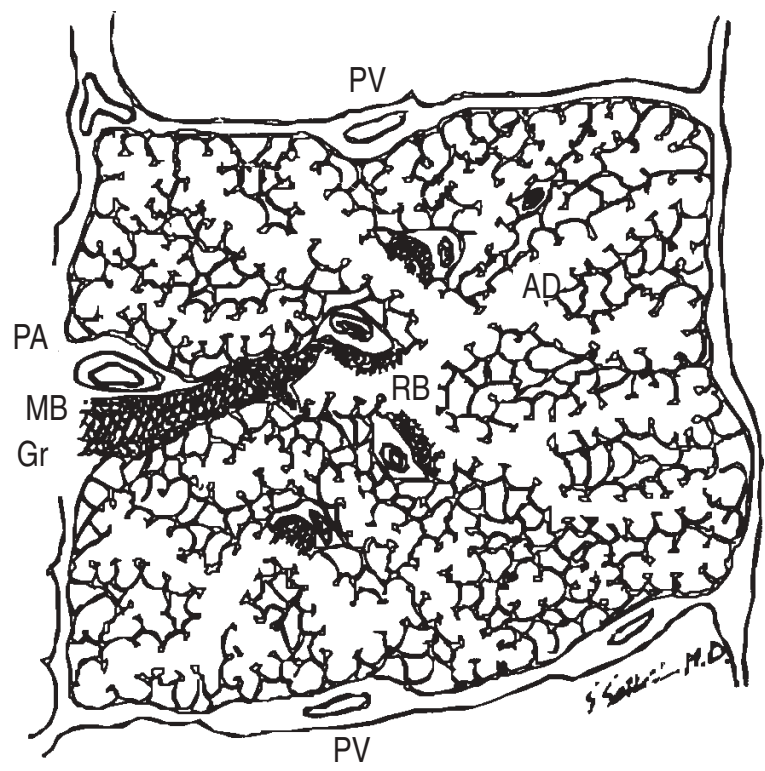

Fig. 13. - Schematic reconstruction of serial sections focused on the primary lesions, showing that the lumina of membranous bronchioli are obliterated by granulation tissues, but that the distal respiratory bronchioli are spared and alveolar spaces are slightly overinflated. AD: alveolar duct; Gr: granulation tissues; MB: membranous bronchiole; PA: pulmonary artery; PV: pulmonary vein; RB: respiratory bronchiole.

\section{Discussion}

\section{Pathogenesis of diffuse panbronchiolitis}

DPB is characterized by chronic inflammation localized mainly in the region of the respiratory bronchiole just distal to the terminal bronchiole, known as the transitional zone between the airway and the pulmonary parenchyma. This transitional zone features its own particular structure, respiratory mechanics, gas transport and defence mechanism. The lesions are characterized by respiratory bronchiolitis and peribronchiolitis, which are diffusely disseminated throughout both lungs, especially in the lower lobes. The existence of this disease, as distinguished from bronchial asthma, chronic bronchitis, chronic pulmonary emphysema, bronchiectasis or alveolitis, has been noted since 1969 in Japan [5]. More than 1,000 cases of probable DPB and 82 histologically confirmed cases have been reported in Japan [7]. DPB shows a predilection for males, typically in the fourth to fifth decades of life. At onset, affected patients present with subacute signs and symptoms of progressive airway obstruction.

The aetiology of DPB is as yet unknown. However, there have been increasing reports on cases of DPB observed in the same family [13,14]. It is well known that there is a high incidence of chronic parasinusitis affecting various members of the same family. Analysis of HLA in patients with DPB demonstrated that HLA-B54 was found more frequently in 38 DPB cases $(63.2 \%)$ than in 184 healthy controls (11.4\%) [15]. According to histocompatibility testing, HLA-B54 was found specifically in Japanese $(14.1 \%)$, Chinese $(10 \%)$ and Korean $(2.8 \%)$ subjects but not in Caucasians [16, 17].

Therefore, DPB may be an ethnically specific disease with a gene controlling susceptibility linked with a Japa- 
nese-specific HLA antigen. The association of RA with HLA-DR4 is well established in various ethnic groups including the Japanese [18, 19]. Since HLA-B54 is correlated with DR4 as an extended haplotype, both DPB and RA have the same HLA haplotype correlation which includes B54 and DR4 [20]. Therefore, it is likely that these two diseases may occur together. Although HLAB54 and -DR4 were not examined in this study, further analyses are necessary to clarify the correlation between HLA typing and DPB associated with RA.

\section{Pathogenesis of obliterative bronchiolitis}

Although it is widely accepted that DPB is a discrete and unique syndrome, there is considerable overlap between DPB and other obstructive lung diseases including $\mathrm{OB}$. OB is characterized by narrowing or obliteration of the membranous bronchioli but the distal respiratory bronchioli are spared [21]. OB shows a predilection for females and sometimes has a more severe and rapidly progressive dyspnoea than DPB. GEDDEs et al. [2] reported the association of progressive airway obliteration in female adults in association with RA and demonstrated that this process was related to OB. Several other reports have demonstrated this association and have further suggested a role for penicillamine in the pathogenesis of this disorder [22, 23].

\section{Clinical diagnostic criteria}

In this study, two patients with DPB and one patient with $\mathrm{OB}$, associated with RA were analysed with regard to clinical features, radiographic images, pulmonary function tests and pathological findings. According to the diagnosis made on the basis of clinical features, DPB was dominant in males and $\mathrm{OB}$ was found in one female. Penicillamine therapy for RA was applied in one patient with DPB but not in the patient with OB. In the radiographic images, small, nodular shadows, tramlines and bronchiolectasis were found throughout both lungs in both patients with DPB and OB. With regard to pulmonary function, obst-ructive impairment was prominent in both DPB and OB. Thus, there were striking similarities between DPB and OB in clinical features, radiographic images and the pulmonary function tests, however, histopathological features obtained by reconstructing the lung specimens demonstra-ted distinct differences between these two diseases. The primary obstructive lesions were in the respiratory bronchioli in DPB and in the membranous bronchioli in $\mathrm{OB}$.

The radiographic and $\mathrm{CT}$ features of $\mathrm{OB}$ associated with RA, with or without D-penicillamine, are similar to those seen with idiopathic OB. Hyperinflation is the most common abnormality and small nodules may be seen [24]. Although follicular bronchiolitis (FB) has also been described in RA and is said to be associated with reticulonodular opacities of the chest radiograph [25, 26], no lesions consistent with FB were found in the three autopsy cases. Thus, this study suggested that the airway involvement in patients with RA could be divided into three kinds of bronchiolitis: DPB, OB and FB.
Five patients (four Whites and one Hispanic) in the USA were identified as having DPB in a recent report [27]. Therefore, increased awareness of DPB associating with or without underlying diseases in the differential diagnosis of bronchiolitis would probably increase the diagnostic yield in the West.

\section{Treatment and prognosis}

The 5-yr survival from the onset of respiratory symptoms in patients with DPB has improved markedly from $62.8 \%$ to $91.4 \%$ since the introduction of erythromycin therapy for DPB in the past 10 yrs in Japan [28, 29]. It is not likely that erythromycin has an antibacterial mechanism. Other mechanisms have been proposed, such as antiinflammatory or immunomodulatory effects, decreased polymorphonuclear leukocyte-directed migration and suppression of hypersecretion [30-32]. In this study, erythromycin was not applied to all patients because they died before the introduction of macrolide therapy for DPB. Corticosteroids rather than erythromycin may be of benefit in patients with OB. It may be important to institute these treatments early in the course of the illness, before irreversible structural changes can develop. However, if a patient with $\mathrm{OB}$ does not respond to corticosteroids, lung transplantation may be a new therapeutic modality for such end-stage patients and has been applied to one patient with OB, as reported recently [33].

\section{Conclusions}

Although it has been established that obliterative bronchiolitis is associated with rheumatoid arthritis, the association of diffuse panbronchiolitis in these patients may simply be coincidental, but the striking similarities between obliterative bronchiolitis and diffuse panbronchiolitis suggest that a real interrelationship may exist between diffuse panbronchiolitis lesions and rheumatoid arthritis. The differentiation of these two disease entities, although very difficult according to the present clinical diagnostic criteria, is very significant for deciding the appropriate methods of treatment in bronchiolitis associated with rheumatoid arthritis, and such differentiation is only possible by analysing the histopathological findings of the affected lung.

\section{References}

1. Gordon DA, Broder I, Hyland RH. Rheumatoid arthritis. In: Cannon GW, Zimmerman GA, eds. The Lung in Rheumatic Diseases. New York, Marcel Dekker, 1990; pp. 229-259.

2. Geddes DM, Corrin B, Brewerton DA, Davies RJ, Turner-Warwick M. Progressive airway obliteration in adults and its association with rheumatoid disease. $Q J$ Med 1977; 184: 427-444.

3. Turton CW, Williams G, Green M. Cryptogenic obliterative bronchiolitis in adults. Thorax 1981; 36: 805-810.

4. King TE Jr. Bronchiolitis obliterans. In: Schwarz MI, King TE Jr, eds. Interstitial Lung Disease, 2nd Edn. Philadelphia, PA, Mosby Year Book, 1993; pp. 463-495.

5. Yamanaka A, Saiki S, Tamura S, Saito K. The problems 
in chronic obstructive pulmonary disease: special reference to diffuse panbronchiolitis. Intern Med 1969; 23: 442-451 (in Japanese).

6. Homma H. Diffuse panbronchiolitis (diffuse respiratory bronchiolitis) - a disease of the transit zone in the lung. Jpn J Intern Med 1976; 65: 645-659 (in Japanese).

7. Homma H, Yamanaka A, Tanimoto S, et al. Diffuse panbronchiolitis. A disease of the transitional zone of the lung. Chest 1983; 83: 63-69.

8. Sugiyama Y, Saitoh K, Kano S, Kitamura S. An autopsy case of diffuse panbronchiolitis accompanying rheumatoid arthritis. Respir Med 1996; 90: 175-177.

9. Homma S, Kishi K, Tsuboi E, et al. Bronchiolitis in rheumatoid arthritis. Eur Respir J 1995; 8: 132S.

10. Homma H. Annual report on the study of diffuse disseminated lung disease. Grant-in-Aid from the Ministry of Health and Welfare in Japan, 1982.

11. Tanimoto H, Nakata K. Present status of the study on DPB. Igaku-no-Ayami 1982; 121: 257-263 (in Japanese).

12. Arnett FC, Edworthy SM, Bloch DA, et al. The American Rheumatism Association 1987 revised criteria for the classification of rheumatoid arthritis. Arthritis Rheum 1988; 31: 315-324.

13. Kinjo Y, Ueda Y, Okada H, Muraoka F, Kadota T, Hara $\mathrm{K}$. Two cases of chronic diffuse panbronchiolitis in one family. Jpn J Chest Dis 1975; 35: 195-202 (in Japanese).

14. Suzuki M, Usui K, Tamura N, et al. Familial cases of diffuse panbronchiolitis. Jpn J Thorac Dis 1981; 19: 645651 (in Japanese).

15. Sugiyama Y, Kudoh S, Maeda H, Suzaki H, Takaku F. Analysis of HLA antigens in patients with diffuse panbronchiolitis. Am Rev Respir Dis 1990; 141: 1459-1462.

16. Terasaki PI. Histocompatibility testing 1980. Los Angeles, CA, UCLA Tissue Typing Laboratory, 1980; p. 959.

17. Okimoto K, Nakano Y, Matsumoto H. IgG heavy-chain $(\mathrm{Gm})$ allotypes and HLA antigens in insulin-dependent diabetes mellitus in Korea. Tohoku J Exp Med 1983; 141: Suppl., 283-287.

18. Radoux V, Menard HA, Begin R, Decary F, Koopman WJ. Airway disease in rheumatoid arthritis patients. One element of a general exocrine dysfunction. Arthritis Rheum 1987; 30: 249-256.

19. Maeda H, Juji T, Mitsui H, Sonozaki H, Okitsu K. HLA DR4 and rheumatoid arthritis in Japanese people. Ann Rheum Dis 1981; 40: 299-302.

20. Sugiyama Y, Ohno S, Kano S, Maeda, Kitamura S. Diffuse panbronchiolitis and rheumatoid arthritis: a possible correlation with HLA-B54. Intern Med 1994; 33: 612-614.

21. Yamanaka A, Maeda M, Yamamoto R. Bronchiolitis obliterans. Jpn J Chest Dis 1986; 45: 539-554 (in Japanese).

22. Murphy KC, Atkins CL, Offer RC, Hogg JC, Stein HB. Obliterative bronchiolitis in two rheumatoid arthritis patients treated with penicillamine. Arthritis Rheum 1981; 24: 557-560.

23. Penny WJ, Knight RK, Rees AM, Thomas AL, Smith AP. Obliterative bronchiolitis in rheumatoid arthritis. Ann Rheum Dis 1982; 41: 469-472.

24. Lynch DA. Imaging of small airways diseases. In: King TE Jr, ed. Clinics in Chest Medicine. Bronchiolitis. Philadelphia, PA, WB Saunders, 1993; pp. 623-634.

25. Yousem SA, Colby TV, Carrington CB. Follicular bronchitis/bronchiolitis. Hum Pathol 1985; 16: 700-706.

26. Kinoshita M, Higashi T, Tanaka C, Tokunaga N, Ichikawa Y, Oizumi K. Follicular bronchiolitis associated with rheumatoid arthritis. Intern Med 1992; 31: 674-677.

27. Fitzgerald JE, King TE Jr, Lynch DA, Tuder RM, Schwarz MI. Diffuse panbronchiolitis in the United States. Am J Respir Crit Care Med 1996; 154: 497-503.

28. Nagai H, Shishido H, Yoneda R, Yamaguchi E, Tamura A, Kurashima A. Long-term low-dose administration of ery-thromycin to patients with diffuse panbronchiolitis. Respiration 1991; 58: 145-149.

29. Kudoh S, Azuma A, Yamamoto M, Izumi T, Tamura M, Ando M. Distinguished improvement of survival times of the patients with diffuse panbronchiolitis treated with 14-membered-ring macrolides. Am J Respir Crit Care Med 1996; 153: A275.

30. Kadota J, Sakito O, Kohno S, et al. A mechanism of erythromycin treatment in patients with diffuse panbronchiolitis. Am Rev Respir Dis 1993; 147: 153-159.

31. Goswami SK, Kivity S, Marom Z. Erythromycin inhibits respiratory glycoconjugate secretion from human airways in vitro. Am Rev Respir Dis 1990; 141: 72-78.

32. Tamaoki J, Isono K, Sakai N, Kanemura T, Konno K. Erythromycin inhibits $\mathrm{Cl}$ secretion across canine tracheal epithelial cells. Eur Respir J 1992; 5: 234-238.

33. Boehler A, Vogt P, Speich R, Weder W, Russi EW. Bronchiolitis obliterans in a patient with localized scleroderma treated with D-penicillamine. Eur Respir J 1996; 9: 1317 1319. 